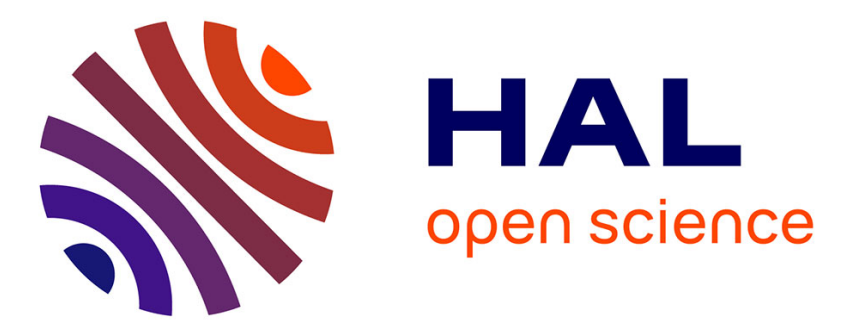

\title{
Fatigue in early axial spondyloarthritis. Results from the French DESIR cohort
}

Laure Gossec, Maxime Dougados, Maria-Antonietta D 'Agostino, Bruno Fautrel

\section{- To cite this version:}

Laure Gossec, Maxime Dougados, Maria-Antonietta D 'Agostino, Bruno Fautrel. Fatigue in early axial spondyloarthritis. Results from the French DESIR cohort. Joint Bone Spine, 2016, 83 (4), pp.427-431. 10.1016/j.jbspin.2015.07.012 . hal-01615246

\section{HAL Id: hal-01615246 https://hal.sorbonne-universite.fr/hal-01615246}

Submitted on 12 Oct 2017

HAL is a multi-disciplinary open access archive for the deposit and dissemination of scientific research documents, whether they are published or not. The documents may come from teaching and research institutions in France or abroad, or from public or private research centers.
L'archive ouverte pluridisciplinaire HAL, est destinée au dépôt et à la diffusion de documents scientifiques de niveau recherche, publiés ou non, émanant des établissements d'enseignement et de recherche français ou étrangers, des laboratoires publics ou privés. 
Fatigue in early axial spondyloarthritis. Results from the French DESIR cohort.

Authors: Laure Gossec, MD, PhD ${ }^{1}$, Maxime Dougados, MD ${ }^{2}$, Maria-Antonietta D’Agostino, $\mathrm{MD}, \mathrm{PhD},{ }^{3}$, Bruno Fautrel, MD, PhD ${ }^{1}$.

\section{Affiliations:}

1: Sorbonne Universités, UPMC Univ Paris 06, Institut Pierre Louis d'Epidémiologie et de Santé Publique, GRC-UPMC 08 (EEMOIS); AP-HP, Pitié Salpêtrière Hospital, Department of rheumatology, Paris, France

2: Paris Descartes University, Rheumatology Department, Cochin Hospital, AP-HP; INSERM (U1153): Clinical Epidemiology and Biostatistics, PRES Sorbonne Paris-Cité, Paris, France.

3: Simone Veil Faculty of Medicine, University of Versailles-Saint-Quentin-en-Yvelines; INSERM U1173, Laboratoire d'Excellence INFLAMEX, 78180 Montigny-leBretonneux; Rheumatology Department, Ambroise Paré Hospital, Assistance Publique-Hôpitaux de Paris, 92100 Boulogne-Billancourt, France

Corresponding author: Pr. Laure Gossec, Hôpital Pitié-Salpétrière, Service de Rhumatologie, 47-83, boulevard de l'Hôpital - 75013 Paris France

laure.gossec@aphp.fr $\quad$ Tel: $+\underline{33142178421}$ Fax: +33142177959

Running head: Fatigue in early axSpA

Word count for the manuscript: 2117. 
Abstract (word count: 247, limit 250)

Introduction: Fatigue is frequent in long-standing axial spondyloarthritis (axSpA); its frequency in early axSpA and its causes are unclear. The objective was to evaluate the magnitude of fatigue in early axSpA and to assess if fatigue appeared more strongly associated with patient- or with disease-related characteristics.

Patients and Methods: Patients were assessed in DESIR, a national observational cohort of patients with recent (<3 years duration) inflammatory back pain suggestive of axSpA. Magnitude of fatigue was assessed by a numeric rating scale (0-10) over one year. Factors associated with high fatigue $(>=5 / 10)$ at 12 months were assessed by univariate and multivariate logistic regression, for patients fulfilling the ASAS axSpA criteria.

Results: Of the 708 patients, 486 fulfilled the ASAS criteria for axSpA: mean age $33 \pm 9$ years; $244(50 \%)$ males. Magnitude of fatigue was high at baseline (mean fatigue, $5.7 \pm 2.3$ ) and decreased only slightly over the first year, and was overlapping in patients fulfilling the ASAS criteria or not. High fatigue at 12 months was well explained (variance explained, 0.84) by a higher ASDAS-CRP (odds ratio, OR, 3.05 [95\% confidence interval, Cl, 2.27-4.12], p<0.0001), higher Bath Anylosing Spondylitis Patient Global BAS-G (OR, 3.51 [95\% Cl, 2.08-6.02], $\mathrm{p}<0.0001)$ and with borderline significance, female gender $(\mathrm{OR}, 1.65[95 \% \mathrm{Cl}, 1.00-2.71]$, $p=0.049)$.

Conclusion: Fatigue levels were high in this population, both for patients fulfilling or not, the ASAS criteria for axSpA. High fatigue was closely related to disease-related variables, indicating fatigue may be an integral part of the disease process in axSpA.

Key words: spondyloarthritis / ankylosing spondylitis, fatigue, quality of life, BASDAI. 


\section{Introduction}

Fatigue is an important symptom in patients with chronic diseases, including rheumatic diseases and has been recently explored in rheumatoid arthritis (RA) and in psoriatic arthritis (PsA) [1-3]. It is a subjective experience that can be described as an overwhelming, sustained sense of dysfunctional exhaustion unrelated to effort and poorly dissipated with appropriate rest [4-5]. Fatigue impacts rheumatic patients' quality of life, and therefore, may involve significant economic consequences for society [6].

In long-standing axial spondyloarthritis ( $\operatorname{axSpA})$, fatigue seems to be frequent, with up to $50-65 \%$ of the patients reporting they feel fatigued [7-12]. Indeed, fatigue is recognised as a marker of axSpA since it is included in the Bath Ankylosing Spondylitis Disease Activity Index (BASDAI), a widely used index for disease activity [13]. However, the magnitude of fatigue in early axSpA has not been established. It is possible that fatigue levels could be different in early disease since spinal ankylosis usually does not exist at this stage and quality of life may be less altered.

The causes of fatigue in inflammatory rheumatisms such as axSpA or RA are unclear; fatigue in axSpA is diversely reported as being related either to patient characteristics, e.g., demographic, psychological and social factors, or to disease characteristics, e.g. disease activity. [10, 12, 14-15].

Thus, although fatigue is reported as frequent and important in $S p A$, its cause remains unclear and its presence in early SpA and in the different subgroups of SpA (predominant axial form or not, with or without radiographic sacro-iliitis) has been very little studied [12].

The objectives of the present study were to evaluate the magnitude of fatigue in early $\mathrm{SpA}$ (and in the different subtypes of $\mathrm{SpA}$ ) and to assess if fatigue appeared more strongly associated with patient- or with disease-related characteristics. 


\section{Patients and Methods}

Study design and patients: DESIR [16] is an observational prospective, multi-centre cohort of patients with inflammatory back pain suggestive of axSpA of less than 3 years duration. Treatments are not-protocolised and left to the judgment of the treating rheumatologist.

\section{$\underline{\text { Assessment of fatigue }}$}

Fatigue was assessed by a numeric rating scale (NRS), range $0-10$, during the first year of follow-up (i.e. at inclusion in the cohort, then at 6 and 12 months), by using the first question of the BASDAI: "How would you describe the overall level of fatigue / tiredness you have experienced in the past week?" [13]. High fatigue was defined (as has been done by other authors) as a fatigue $>=5 / 10[10,11]$.

\section{Factors associated with fatigue}

The association between high fatigue levels at 12 months, and other factors was analysed. The factors included (a) patient-related characteristics at baseline: demographic variables (age, gender, symptom duration, ethnicity), familial status (married or not, number of children) and years of education as a surrogate for socio-economic status; (b) disease activity-related characteristics at 12 months: disease activity variables (ASAS Disease Activity Score: ASDAS-CRP [17], Bath Ankylosing Spondylitis Patient Global Score: BAS-G, and Health Assessment Questionnaire adapted to AxSpA: HAQ-AS), and (c) other disease characteristics (HLA-B27 positivity, disease subtype according to the physician, extra-articular involvement yes/no, entheseal pain yes/no as assessed by the Maastricht Ankylosing Spondylitis Enthesitis Score, and sacroiliitis on radiographs or magnetic resonance imaging, according to local reading of the imaging).

\section{Statistical analyses}


In the whole population: fatigue magnitude was assessed by descriptive statistics at baseline, 6 months and one year, in all patients in DESIR then on the subgroups fulfilling or not at baseline, the Assessment of SpondyloArthritis (ASAS) classification criteria for axSpA [18] and its different arms i.e., clinical versus imaging arms, and also according to disease subtype (purely axial versus axial+peripheral versus undifferentiated, as defined by the investigators).

At one year of follow-up: a univariate then multivariate logistic regression was performed to explain high fatigue, defined as fatigue NRS $>=5 / 10$ at 12 months, by the explanatory variables, through a stepwise selection. BASDAl was not entered in the analyses since the fatigue question was an integral part of the BASDAI and since correlation with ASDAS-CRP are high. The Bath Ankylosing Spondylitis Functional Index was also not analysed since highly correlated to the HAQ-AS. This analysis was performed in the group of patients fulfilling the ASAS criteria, and for exploratory purposes, after exclusion of BAS-G since patient global assessments and fatigue are often correlated, and also in the whole group of patients.

There was no imputation of missing data. The Statistical Analysis System (SAS) version 9.2 was used. 


\section{Results}

\section{Patient characteristics}

Of the 708 DESIR patients (mean \pm standard deviation age $34 \pm 9$ years; $327(46 \%)$ males), 486 fulfilled the ASAS criteria for axSpA at baseline (mean age 33 \pm 9 years; 244 (50\%) males). Symptom duration was short and BASDAI was high at inclusion in the cohort (Table 1); 206 (30.1\%) had elevated C-reactive protein. Although all patients presented with axial symptoms, the investigators characterised the disease as axial $(\mathrm{N}=349)$, axial+peripheral $(\mathrm{N}=41)$, undifferentiated $(\mathrm{N}=225)$ or other/unclear $(\mathrm{N}=93)$. At one year of follow-up, 450 (72.9\%) patients were treated with non-steroidal anti-inflammatory drugs, and $158(22.3 \%)$ were treated with anti-tumor necrosis factor drugs.

Magnitude of fatigue was high at baseline (mean fatigue, $5.7 \pm 2.3$ ). In patients fulfilling the ASAS criteria or not, numerical differences were noted (respectively, mean fatigue $5.5 \pm 2.4$ and 6.0 \pm 2.2 ); however there was significant overlap between the 2 groups; median values of fatigue were identical in both groups (respectively, 6 [interquartile range 4-7] and 6 [5-8]) (Table 2). There were however differences according to the arms of the ASAS criteria: mean fatigue was $4.7 \pm 2.5$ in the conventional radiography sacroiliitis arm ,i.e., ankylosing spondylitis $\operatorname{arm}(\mathrm{N}=50), 5.6 \pm 2.3$ in the MRI sacroiliitis (without radiography sacroiliitis) arm $(\mathrm{N}=98)$, versus $5.9 \pm 2.2$ in the non-radiographic arm $(\mathrm{N}=197)(\mathrm{p}=0.0009$ versus the ankylosing spondylitis arm).

Fatigue levels according to the disease subtype were similar (in predominantly axial disease, mean fatigue $5.6 \pm 2.4$, in peripheral forms $6.0 \pm 2.2$ and in undifferentiated forms $5.7 \pm 2.3$, respectively; $p=0.6$ ).

Fatigue decreased significantly but slightly over the first year of follow-up (mean fatigue at one 
year, 4.9 $\pm 2.6, \mathrm{p}=0.008$ ) (Table 2). This was similar to the decrease in pain (data not shown).

\section{Factors associated with high fatigue levels at one year}

Among the 428 patients fulfilling the ASAS criteria for axSpA and with full data available for this analysis, high fatigue level (>=5/10) concerned $210(49 \%)$ patients at 12 months.

In univariate analysis, fatigue was associated with female gender $(p<0.0001)$, higher ASDASCRP $(p<0.0001)$, higher BAS-G $(p<0.0001)$, higher HAQ-AS $(p<0.0001)$, shorter length of schooling $(p=0.003)$ and negativity of HLA B27 $(p=0.026)$.

In multivariate analysis, high fatigue at 12 months was well explained (variance explained, 0.84) by the following independent elements (Table 3): higher ASDAS-CRP (odds ratio, OR, 3.05 [95\% confidence interval, $\mathrm{Cl}, 2.27-4.12], \mathrm{p}<0.0001)$, higher BAS-G (OR, 3.51 [95\% Cl, 2.08-6.02], $\mathrm{p}<0.0001)$ and with borderline significance, female gender $(\mathrm{OR}, 1.65$ [95\% $\mathrm{Cl}$, 1.00-2.71], $p=0.049)$. Patient-related characteristics apart from gender, were not significant to explain fatigue at 12 months in this multivariate analysis. When excluding BAS-G from the analysis, the explanatory factors remained disease-related (variance explained, 0.82; Table 3). In the whole population, high fatigue was explained by ASDAS-CRP (OR, 3.12 [95\% Cl, 2.314.20], $p<0.0001)$, BAS-G (OR, 2.42 [95\% CI, 1.53-3.84], $p=0.00021)$ and HAQ-AS (OR for an increase of $0.2,1.15$ [95\% Cl, 1.03-1.30], $\mathrm{p}=0.017$ ) (variance explained, 0.84 ). 


\section{Discussion}

Fatigue levels were high in this large cohort of patients with symptoms suggestive of early axSpA, independently of the fulfillment of the ASAS criteria. High fatigue at one year was closely related to disease activity rather than to patient-related variables, supporting the concept that fatigue is an integral part of disease activity also in early axSpA.

This is to our knowledge, the first study exploring fatigue and its associated factors in early axSpA. Due to reference shifts, symptoms such as fatigue may be very different in early disease; however fatigue levels here were similar to those observed in established axSpA.

This study has strengths and weaknesses. The study sample was large, and represents the spectrum of patients with inflammatory back pain suggestive of axSpA in France [16]. Nonetheless, fatigue may be influenced by cultural background [19]; thus studies in other countries are warranted. The BASDAI fatigue question was used to assess fatigue, rather than a specific fatigue scale such as the Functional Assessment of Chronic Illness Therapy Fatigue scale (FACIT-F) for example. However, good correlations have been shown between the fatigue NRS and more complex scales [10, 20]. Finally, some important elements such as sleep disturbances, and psychological status including anxiety/depression were not analysed in the present study.

Fatigue is a frequent symptom in rheumatic diseases, with around half the patients describing high fatigue levels, in RA as well as in PsA or axSpA [2-4, 10]. In established axSpA specifically, fatigue levels appeared very similar to the ones observed in the present early disease population $[10,12]$. Fatigue levels in axSpA should however be put in context using the healthy population as comparator since fatigue is frequently experienced by healthy adults with a prevalence comprised between 14 and $25 \%$ and female predominance [11]. 
In the present study, although fatigue levels decreased slightly after inclusion in the cohort, $55 \%$ of patients still had a fatigue $>=5 / 10$ at one year. The decrease of fatigue over the first year of follow-up in DESIR, is possibly due to the treatments given, or to an effect of regression towards the mean. Similar observations have been made in early RA cohorts [21]. In the present cohort, use of anti-TNF therapies was low over the first year of follow-up, and was not specifically analysed here. The high levels of fatigue seen in $\operatorname{axSpA}$ and potential consequence of fatigue, are offset by few publications on this subject: a systematic literature review evidenced only 3 papers on fatigue in SpA over a 10-year period in Europe, versus 16 papers in RA over the same period [22].

The present results indicate fatigue levels were similar in this population fo patients with symptoms suggestive of axSpA, whether the patients fulfilled or not, the ASAS criteria for axSpA. This indicates fatigue should not be used as a diagnostic element when faced with inflammatory back pain suggestive of axSpA. Although non-radiographic axSpA patients had higher levels of fatigue than the radiographic ones, there was important overlap between these populations as well as with the patients not fulfilling the axSpA classification criteria [12]. The question of concomitant fibromyalgia in patients with non-radiographic axSpA could be raised here.

Fatigue is difficult to deal with for rheumatologists. Firstly, because as we have shown here, fatigue does not seem to be helpful for diagnosis/ classification. Secondly because fatigue is not always a marker of disease activity thus does not always lead to diseasemodifying drug changes; and thirdly because its treatment, as isolated symptom, is difficult.

Fatigue was closely related to disease activity rather than to patient-related variables in the present study. Female gender appears to be associated with higher fatigue, both in the general population [11], and in established axSpA [12]. Fatigue in established axSpA has 
been reported as being related to demographic, psychological and social factors, but also to disease activity. [10, 12, 14-15, 23]. We found, like other authors, that fatigue was highly associated to other patient-reported outcomes such as patient global assessment and quality of life [10,12]: this is one of the difficulties of dealing with fatigue in terms of psychometric properties, but also indicates the potential importance of fatigue from the patient's perspective [24]. To try to distinguish between disease-related causes and patient-reported symptoms in the origin of fatigue we performed analyses first including then excluding patient global assessment (BAS-G), and we used the ASDAS-CRP as a marker of disease activity. The results still evidenced as associated factors, mainly outcomes related to the disease rather than the patient. Thus we could hypothesize fatigue appears more closely related to the disease process in SpA than in RA. It is however noteworthy that fatigue was not selected in the ASDAS score [17] suggesting low predictive validity, at least in established disease.

To date there are no specific treatments targeting fatigue in axSpA. Indeed, the mechanisms underlying fatigue in axSpA remain poorly understood, and may involve the inflammatory process / pro-inflammatory cytokines, and/or psychological distress for example. A recent study based on $3 \mathrm{~T}$-magnetic resonance imaging of the brain indicated fatigue in axSpA may involve sensory salience and attention brain networks. [19] In any case, the efficacy of the usual treatments prescribed by rheumatologists, including biologics, on fatigue, is only moderate in RA [25]. In RA also, non-pharmacological interventions such as cognitive behavioural therapy have been shown efficacious; such interventions remain to be assessed in axSpA [26].

In conclusion, fatigue is a frequent symptom also in early axSpA which appears strongly associated to the disease process; consequences of and treatments for this fatigue should be further evaluated. 


\section{Acknowledgments}

The DESIR cohort is conducted under the control of Assistance Publique-Hopitaux de Paris via the Clinical Research Unit Paris-Centre and under the umbrella of the French Society of Rheumatology and INSERM (Institut National de la Santé et de la Recherche Médicale). The database management is performed within the department of epidemiology and biostatistics (Professor Jean-Pierre Daurès, D.I.M., Nîmes, France).

We wish to thank the different regional participating centres : Pr Maxime Dougados (Paris Cochin B), Pr André Kahan (Paris - Cochin A), Pr Olivier Meyer (Paris - Bichat), Pr Pierre Bourgeois (Paris - La Pitié-Salpetrière), Pr Francis Berenbaum (Paris - Saint Antoine), Pr Pascal Claudepierre (Créteil), Pr Maxime Breban (Boulogne Billancourt), Dr Bernadette SaintMarcoux (Aulnay-sous-Bois), Pr Philippe Goupille (Tours), Pr Jean-Francis Maillefert (Dijon), Dr Xavier Puéchal (Le Mans), Pr Daniel Wendling (Besançon), Pr Bernard Combe (Montpellier), Pr Liana Euller-Ziegler (Nice), Pr Philippe Orcel (Paris - Lariboisière), Pr Pierre Lafforgue (Marseille), Dr Patrick Boumier (Amiens), Pr Jean-Michel Ristori (Clermont-Ferrand),

Dr Nadia Mehsen (Bordeaux), Pr Damien Loeuille (Nancy), Pr René-Marc Flipo (Lille), Pr Alain Saraux (Brest), Pr Corinne Miceli (Le Kremlin Bicêtre), Pr Alain Cantagrel (Toulouse), Pr Olivier Vittecoq (Rouen).

We also wish to thank Simon Paternotte, statistician, previously from Cochin hospital, Paris and Adrien Etcheto, statistician, Cochin hospital Paris for statistical help.

Funding: DESIR cohort: An unrestricted grant from Wyeth Pharmaceuticals was allocated for the first 5 years of the follow-up of the recruited patients in the DESIR cohort.

Present study: this work was supported by Pfizer through an unrestricted Passerelle Grant.

Disclosures of interest: none relevant to this work. 


\section{References}

1. Jason LA, Evans $M$, Brown M, Porter $N$. What is fatigue? Pathological and non pathological fatigue. PM R 2010;2(5):327-31.

2. Kirwan JR, Minnock P, Adebajo A, et al. Patient perspective: fatigue as a recommended patient centered outcome measure in rheumatoid arthritis. J Rheumatol. 2007;34(5):1174-7.

3. Husted JA, Tom BD, Schentag CT, Farewell VT, Gladman DD.. Occurrence and correlates of fatigue in psoriatic arthritis. Ann Rheum Dis 2009; 68: 1553-58.

4. Hewlett S, Cockshott Z, Byron M, et al. Patients' perceptions of fatigue in rheumatoid arthritis: overwhelming, uncontrollable, ignored. Arthritis Rheum. 2005;53(5):697-702.

5. Günaydin R., Göksel Karatepe A., Çeşmeli N., Kaya T. Fatigue in patients with ankylosing spondylitis: relationships with disease-specific variables, depression, and sleep disturbance. Clin Rheumatol 2009; 28:1045-1051.

6. Carlotto A, Hogsett VL, Maiorini EM, Razulis JG, Sonis ST. The economic burden of toxicities associated with cancer treatment: review of the literature and analysis of nausea and vomiting, diarrhoea, oral mucositis and fatigue. Pharmacoeconomics. 2013;31(9):753-66.

7. Ibn Yacoub Y, Amine B, Laatiris A, Abouqal R, Hajjaj-Hassouni N. Assessment of fatigue in Moroccan patients with ankylosing spondylitis. Clin Rheumatol 2010; 29:1295-1299.

8. Da Costa D, Dritsa M, Ring A, Fitzcharles MA. Mental Health status and leisure-time physical activity contribute to fatigue intensity in patients with spondylarthropathy. Arthritis Rheum 2004; 51: 1004-1008.

9. Turan Y, Duruöz M, Bal S, Guvenc A, Cerrahoglu L, Gurgan A. Assessment of fatigue in patients with ankylosing spondylitis. Rheumatol Int 2007; 27:847-852.

10. Van Tubergen A, Coenen J, Landewe R, et al. Assessment of fatigue in patients with ankylosing spondylitis: a psychometric analysis. Arthritis Rheum 2002; 47:8-16.

11. Dagfinrud H, Vollestad N, Loge J, Kvien T, Mengshoel AM. Fatigue in patients with Ankylosing Spondylitis: A comparison With the general population and associations With Clinical and Self-Reported Measures. Arthritis Rheum 2005; 53: 5-11. 
12. Bianchi WA, Elias FR, Carneiro S, et al. Assessment of fatigue in a large series of 1492 Brazilian patients with Spondyloarthritis. Mod Rheumatol. 2014;24(6):980-4.

13. Garrett S, Jenkinson T, Kennedy LG, Whitelock H, Gaisford P, Calin A. A new approach to defining disease status in ankylosing spondylitis: the Bath Ankylosing Spondylitis Disease Activity Index. J Rheumatol. 1994;21:2286-91.

14. Dernis-Labous E, Messow M, Dougados M. Assessment of fatigue in the management of patients with ankylosingspondylitis. Rheumatology 2003; 42:1523-1528.

15. Calin A, Edmuns L, Kennedy LG. Fatigue in ankylosing spondylitis-Why is it ignored? J Rheumatol 1993;20: 991-5.

16. Dougados M, d'Agostino MA, Benessiano J, et al. The DESIR cohort: a 10-year followup of early inflammatory back pain in France: study design and baseline characteristics of the 708 recruited patients. Joint Bone Spine. 2011;78:598-603

17. Machado P, Landewé R, Lie E, et al. Ankylosing Spondylitis Disease Activity Score (ASDAS): defining cut-off values for disease activity states and improvement scores. Ann Rheum Dis. 2011;70(1):47-53.

18. Rudwaleit M, van der Heijde D, Landewé R, et al. The development of Assessment of SpondyloArthritis international Society classification criteria for axial spondyloarthritis (part II): validation and final selection. Ann Rheum Dis. 2009;68(6):777-83.

19. Hifinger M, Putrik $P$, Ramiro S, et al. In addition to individual demographic and clinical measures, levels of fatigue are dependent on country of residence. An analysis among 3920 patients from 17 countries (the COMORA study). Ann Rheum Dis 2014;73(Suppl2): 411.

20. Hewlett S, Dures E, Almeida C. Measures of fatigue: Bristol Rheumatoid Arthritis Fatigue Multi-Dimensional Questionnaire (BRAF MDQ), Bristol Rheumatoid Arthritis Fatigue Numerical Rating Scales (BRAF NRS) for severity, effect, and coping, Chalder Fatigue Questionnaire (CFQ), Checklist Individual Strength (CIS20R and CIS8R), Fatigue Severity Scale (FSS), Functional Assessment Chronic Illness Therapy (Fatigue) (FACIT-F), MultiDimensional Assessment of Fatigue (MAF), Multi-Dimensional Fatigue Inventory (MFI), 
Pediatric Quality Of Life (PedsQL) Multi-Dimensional Fatigue Scale, Profile of Fatigue (ProF), Short Form 36 Vitality Subscale (SF-36 VT), and Visual Analog Scales (VAS). Arthritis Care Res (Hoboken). 2011;63 Suppl 11:S263-86.

21. Rat AC, Pouchot J, Fautrel B, Boumier P, Goupille P, Guillemin F. Factors associated with fatigue in early arthritis: results from a multicenter national French cohort study. Arthritis Care Res (Hoboken). 2012;64(7):1061-9.

22. Gossec L, Berenbaum F, Chauvin P, et al. Reporting of patient-perceived impact of rheumatoid arthritis and axial spondyloarthritis over 10 years: a systematic literature review. Rheumatology (Oxford). 2014;53(7):1274-81.

23. Chauffier K, Paternotte S, Burki V, et al. Fatigue in spondyloarthritis: a marker of disease activity. A cross-sectional study of 266 patients. Clin Exp Rheumatol. 2013;31(6):86470.

24. Kiltz U, van der Heijde D, Boonen A, et al. Development of a health index in patients with ankylosing spondylitis (ASAS HI): final result of a global initiative based on the ICF guided by ASAS. Ann Rheum Dis. 2015;74(5):830-5

25. Chauffier K, Salliot C, Berenbaum F, Sellam J. Effect of biotherapies on fatigue in rheumatoid arthritis: a systematic review of the literature and meta-analysis. Rheumatology (Oxford). 2012;51(1):60-8.

26. Hewlett S, Ambler N, Almeida C, et al. Self-management of fatigue in rheumatoid arthritis: a randomised controlled trial of group cognitive-behavioural therapy. Ann Rheum Dis. 2011;70(6):1060-7. 
Table 1. Characteristics of patients in the DESIR cohort at inclusion

\begin{tabular}{|c|c|c|c|}
\hline Characteristic at inclusion & \begin{tabular}{|} 
Whole \\
population \\
$(\mathrm{N}=708)$
\end{tabular} & $\begin{array}{c}\text { ASAS } \\
\text { criteria fulfilled } \\
(\mathrm{N}=486)\end{array}$ & $\begin{array}{l}\text { ASAS criteria } \\
\text { not fulfilled } \\
(\mathrm{N}=206)\end{array}$ \\
\hline Age, years, mean (SD) & $33.7(8.6)$ & $33.0(8.6)$ & $35.4(8.4)$ \\
\hline Males, N (\%) & $327(46.2)$ & $244(50.2)$ & $76(36.9)$ \\
\hline $\begin{array}{l}\text { Symptom duration at inclusion } \\
\text { (months), mean (SD) }\end{array}$ & $18.1(10.4)$ & $18.5(10.6)$ & $17.2(10.0)$ \\
\hline HLA B27 positivity, N (\%)* & $410(58.0)$ & $406(83.7)$ & $3(1.5)$ \\
\hline Radiographic sacro-iliitis, $\mathrm{N}(\%)^{*}$ & $187(27.0)$ & $187(38.9)$ & 0 \\
\hline Peripheral synovitis, $\mathrm{N}(\%)$ & $51(7.2)$ & $35(7.2)$ & $13(6.3)$ \\
\hline Entheseal pain, $\mathrm{N}(\%)$ & $347(49.0)$ & $227(46.7)$ & $114(55.3)$ \\
\hline $\begin{array}{l}\text { Any extra-articular manifestation at } \\
\text { inclusion, } \mathrm{N}(\%)\end{array}$ & $188(26.6)$ & $132(27.2)$ & $53(25.7)$ \\
\hline BASDAI (0-100), mean (SD) & $44.7(20.0)$ & $42.9(20.4)$ & $48.4(18.4)$ \\
\hline ASDAS-CRP, mean (SD) & $2.5(1.0)$ & $2.5(1.1)$ & $2.5(0.9)$ \\
\hline Axial pain NRS (0-10), mean (SD) & $5.0(2.7)$ & $4.7(2.8)$ & $5.6(2.4)$ \\
\hline BASFI (0-100), mean (SD) & $30.4( \pm 22.8)$ & $29.7( \pm 22.5)$ & $32.3( \pm 23.5)$ \\
\hline BAS-G (0-10), mean (SD) & $5.1(2.6)$ & $4.9(2.6)$ & $5.6(2.3)$ \\
\hline
\end{tabular}




\begin{tabular}{|l|l|l|l|}
\hline HAQ-AS (0-3), mean (SD) & $0.6( \pm 0.5)$ & $0.6( \pm 0.5)$ & $0.6( \pm 0.5)$ \\
\hline
\end{tabular}

For 16 patients $(2.2 \%)$ the ASAS classification criteria could not be calculated due to missing data.

SD: standard deviation, NRS: numeric rating scale, BASDAI: Bath Ankylosing Spondylitis Disease Activity Index [13], ASDAS-CRP: ASAS Disease Activity Score-CRP [17], BASFI: Bath Ankylosing Spondylitis Functional Index, BAS-G: Bath Ankylosing Spondylitis Global, HAQ-AS: Health Assessment Questionnaire adapted to axSpA.

* percentages are percentages of available data 
Table 2. Magnitude of fatigue over the first year in the DESIR cohort.

\begin{tabular}{|l|l|l|l|l|}
\hline $\begin{array}{l}\text { Fatigue NRS (0-10), } \\
\text { mean (SD) }\end{array}$ & \multicolumn{1}{|c|}{$\begin{array}{c}\text { Whole } \\
\text { population } \\
\mathbf{( N = 7 0 8 )}\end{array}$} & $\begin{array}{c}\text { ASAS criteria } \\
\text { fulfilled } \\
(\mathbf{N}=\mathbf{4 8 6})\end{array}$ & $\begin{array}{r}\text { ASAS criteria } \\
\text { not fulfilled } \\
(\mathbf{N}=\mathbf{2 0 6})\end{array}$ & $\begin{array}{c}\mathbf{P} \\
\text { value* }^{*}\end{array}$ \\
\hline Baseline & $5.7(2.3)$ & $5.5(2.4)$ & $6.0(2.2)$ & 0.009 \\
\hline After 6 months & $4.9(2.6)$ & $4.7(2.6)$ & $5.5(2.5)$ & 0.001 \\
\hline After 12 months & $4.9(2.6)$ & $4.7(2.6)$ & $5.5(2.4)$ & 0.001 \\
\hline * p-value comparing patients fulfilling or not, the ASAS classification criteria for axSpA at
\end{tabular}

baseline [18] 
Table 3. Factors associated with high fatigue at 12 months of follow-up in the DESIR cohort.

\begin{tabular}{|c|c|c|c|c|}
\hline $\begin{array}{l}\text { Characteristi } \\
\text { c at } 12 \text { months }\end{array}$ & $\begin{array}{l}\text { Level in } \\
\text { 'high fatigue' } \\
\text { patients } \\
(\mathrm{N}=217)\end{array}$ & $\begin{array}{l}\text { Level in } \\
\text { 'low fatigue' } \\
\text { patients } \\
(\mathrm{N}=211)\end{array}$ & $\begin{array}{l}\text { Full model } \\
\text { Odds ratio [95\% } \\
\text { confidence } \\
\text { interval] ( } p \text { value) }\end{array}$ & $\begin{array}{l}\text { Model excluding } \\
\text { BAS-G } \\
\text { Odds ratio [95\% } \\
\text { confidence } \\
\text { interval] ( } p \text { value) }\end{array}$ \\
\hline Female gender & $137(63.1)$ & $80(37.9)$ & $\begin{array}{l}1.65 \quad[1.00-2.71] \\
(0.049)\end{array}$ & $\begin{array}{l}1.85[1.15-2.99] \\
(0.01)\end{array}$ \\
\hline ASDAS-CRP & $2.5( \pm 1.0)$ & $1.5( \pm 0.8)$ & $\begin{array}{l}3.05 \quad[2.27-4.12] \\
(<0.0001)\end{array}$ & $\begin{array}{l}3.01[2.20-4.11] \\
(<0.0001)\end{array}$ \\
\hline BAS-G & $4.8( \pm 2.5)$ & $2.5( \pm 2.2)$ & $\begin{array}{l}3.51 \quad[2.08-6.02] \\
(<0.0001)\end{array}$ & Not included \\
\hline HAQ-AS & $0.66(0.53)$ & $0.25(0.35)$ & Not significant & $\begin{array}{c}2.17[1.14-4.16] \\
(0.02)\end{array}$ \\
\hline
\end{tabular}

Multivariate logistic regression in 428 patients fulfilling the ASAS classification criteria for axSpA and with full data available. Levels of each variable in the high fatigue and low fatigue groups are given for indicative purposes, as $\mathrm{N}$ (\%) or mean (standard deviation). Odds ratios were calculated for an increase of 1.0 of the ASDAS-CRP, for an increase of 5 units for BAS$G$ and for an increase of 0.2 points of HAQ-AS. 